\title{
Revistas, consumos, alimentación y saberes femeninos. La propuesta de Damas y Damitas, Argentina, 1939-1944
}

\section{Women's Magazines, Consumption, Diet and Knowledge. The Damas y Damitas Proposal, Argentina, 1939-1944}

\author{
Paula Caldo \\ Conicet/Universidad Nacional de Rosario \\ paulacaldo@gmail.com
}

\begin{abstract}
Resumen
El presente artículo aborda un aspecto puntual del abanico que se extiende en torno a la problemática de la transmisión de los saberes femeninos: la transmisión escrita del saber culinario y sus connotaciones teóricas, prácticas, performativas y económicas. Específicamente, nos concentraremos en la Argentina en el cruce de las décadas de los treinta y los cuarenta, recorte que coincide con la consolidación de la sociedad de consumo y con la irrupción en el mercado editorial de una revista femenina llamada Damas y Damitas, que tomaremos como referente empírico de nuestro análisis. En dicha publicación recuperamos el accionar de la ecónoma encargada de enseñar a cocinar pero también de prescribir un deber ser y un saber elegir (la marca) a sus congéneres.
\end{abstract}

Palabras clave: Mujeres; sociedad de consumo; transmisión; cocina; economía doméstica.

\section{Abstract}

This article addresses a key aspect of the many issues surrounding the transmission of female knowledge: the written transmission of culinary knowledge and its theoretical, practical, performative and economic aspects. It will focus on Argentina in the late 1930 and early 1940 s, a period that saw the consolidation of the consumer society and the emergence on the publishing market of the women's magazine Damas y damitas, which will serve as the empirical reference for this analysis. In this publication, we find the figure of the bursar responsible for teaching cooking skills, but also for prescribing a particular lifestyle for her peers and teaching them to choose (a particular brand).

Key words: Women; consumer society; transmission; cooking; domestic economy.

Fecha de recepción: 22 de octubre de 2013 Fecha de aceptación: 17 de enero de 2014 


\section{Revistas, consumos, alimentación y saberes femeninos. La propuesta de Damas y Damitas, Argentina, 1939-1944 Paula Caldo}

\section{INTRODUCCIÓN}

E presente artículo propone historiar una serie de connotaciones desprendidas del proceso de feminización de la transmisión escrita del saber culinario en Argentina en la bisagra de las décadas de 1930 y 1940. Justamente, este periodo, marcado por un incipiente proceso de industrialización por sustitución de importaciones, traerá consigo un modo particular de practicar el consumo para los(as) argentinos(as), en el cual las mujeres ocuparon un lugar destacado en tanto principales agentes de compra de productos para el uso doméstico y cotidiano de las familias (alimentos, vestimenta, artículos de limpieza y/o desinfección, etc.) (Rocchi, 1999, t. 2).

En este contexto la intención es mostrar cómo la recurrente publicación en la prensa femenina de recetas culinarias persiguió el cometido tanto de enseñar a cocinar, como de educar al ama de casa y otorgar una salida laboral "políticamente correcta" para las féminas, y también fomentó constantemente el consumo de productos alimenticios. De tal suerte, la mujer fue situada en el corazón de las estrategias del mercado y la cocina se transformó en una práctica marcada por los actos de compra de productos industrializados (envasados, enlatados, marcas, etcétera).

Para darle especificidad histórica a tal proceso se ha construido un andamiaje teórico-metodológico hojaldrado en cuyas capas se cuelan los aportes de la historia sociocultural, la historia de y con mujeres y la historia de la alimentación (Gayol y Madero, 2007; Zemon, 2006). En esta línea la temática se verá enriquecida con las discusiones en torno a procesos de ampliación de públicos lectores, los accesos al mercado editorial así como también de sus características, las prácticas de consumo, el lugar de las mujeres en el espacio público y la popularización de las ecónomas como expertas en saberes vinculados a la economía doméstica.

\section{(ㅇ)(1) $\$$}


Capitalizando el mencionado enfoque se procederá a realizar una lectura crítica e interpretativa de una revista de tirada masiva llamada Damas y Damitas. La misma estuvo destinada a las mujeres de los sectores sociales medios y bajos generalmente de las periferias urbanas, ciudades menores y también zonas rurales. El sistema de suscripción y compra por correo fue la estrategia que garantizó la circulación ampliada de la revista, y el intercambio epistolar entre lectoras y editores también deja ver indicios de ello. ${ }^{1}$ Interesa esta propuesta del mercado editorial porque dentro del abanico de temas que ofrecía destinó un renglón importante a la economía doméstica entendida exclusivamente en términos de cocina. La relación entre mujeres, economía doméstica y cocina cristaliza casi naturalizada en las páginas del semanario y es expresada a partir de la figura de una experta, la profesora Julia E. Bourdieu. Figura que será clave en este análisis.

Ahora bien, desde el momento en que la escritura comenzó a ser un refugio donde resguardar del olvido al conocimiento, junto a los compendios de ciencia y filosofía, entre otros, afloraron los manuales, recetarios y demás formatos textuales destinados a regir sobre las prácticas cotidianas. En esta sintonía, los recetarios de cocina cobraron su razón de ser presentando, mediante una prosa sencilla y concreta, amplios listados de ingredientes, procedimientos y consejos culinarios. En cada receta se libró una batalla entre la intervención humana sobre los ingredientes -materia prima-y los límites que estos pusieron a dicha intervención (Sennett, 2009). La materialidad de determinados alimentos ameritó formas especiales de cocción, combinación, elaboración o cortes que, con el correr del tiempo, compusieron un corpus de saber específico y oriundo de la experiencia concreta: las recetas de cocina.

Pero las recetas de cocina escritas, lejos de contactarnos con las prácticas, nos informan sobre la escritura del saber culinario. Y, si bien estas se expresan en el lenguaje de las acciones, su fuerte no radica en el hacer, sino en poner por escrito lo que se hace (Giard, 2006, t. II). Aquí es interesante recuperar las palabras de Roger Chartier (1999): "hay libros o textos impresos que se convierten en prácticas o en comportamientos para aquellos que los leen y para aquellos que los escuchan leer" (p. 45). En esos textos es preciso buscar el instante en que el hacer escapa al orden del discurso; también resulta per-

${ }^{1}$ Es preciso aclarar que la forma epistolar marcó gran parte de la estructura de las secciones del semanario (más adelante lo describiremos en detalle). El intercambio de epístolas entre editores y lectores revela no sólo la identidad de las lectoras sino la procedencia. Aunque somos conscientes de que las cartas son producto de la escritura y puede haber existido cierta cuota de discrecionalidad o ficcionalización por parte de los(as) editores(as) (Bouvet, 2006).

\section{(ㅇ)(1) $\$$}


tinente preguntarnos por los motivos que conducen a las sociedades a poner por escrito determinadas prácticas del orden cotidiano. Si nos proponemos no confundir decir con hacer, debemos historiar las condiciones sociales que impulsan la necesidad de crear discursos sobre las prácticas. En este punto se hace preciso destejer los motivos culturales que llevaron a depositar en las manos de un determinado grupo de mujeres la escritura de la cocina cotidiana. Decimos determinado porque durante el periodo aquí tratado serán damas provenientes de sectores medios bajos, alfabetizadas, expertas en los saberes del hogar pero también necesitadas de una labor rentada, quienes asumirán el ejercicio de transmitir el saber culinario a sus congéneres.

Como primera cuestión, las recetas de cocina escritas tratadas en este análisis estuvieron destinadas a colaborar con la tarea de transmisión y, por ende, con la educación de las mujeres cocineras y amas de casa orientándolas, principalmente, en la elección de platos e ingredientes. Empero, la antropóloga Luce Giard (2006) considera que los recetarios de cocina no son la vía más adecuada para aprender a cocinar. En un gesto autobiográfico, ella recuerda su experiencia de formación y argumenta: "la solución me pareció evidente: esas cosas, igual que las otras, debían poder aprenderse en los libros; bastaba poder encontrar en la librería una fuente de información simple, rápida, moderna y barata" (t. II, p. 155). Pero, pese a que leyó y releyó esas fórmulas impresas en los libros, había un saber implícito que la marcaba como cocinera. La cocina invade los sentidos y entre ruidos, olores, colores y sabores se experimenta un ejercicio de anamnesis que despierta conocimientos dormidos. En otras palabras, a cocinar se aprende cocinando. De esta forma, el gesto de leer un recetario de cocina desencadena un torbellino de imágenes sensoriales que, al tiempo que encienden el recuerdo, dejan sin efecto el poder de las recetas impresas en beneficio de la experiencia vivida. Entonces, la cocinera abandona la lectura de la receta y, al compás de la acción, sumerge sus manos en los ingredientes. En este punto, cabe preguntarnos si es sólo ese el efecto que se espera de los libros de cocina. Entendemos que no: la cocina escrita estuvo envuelta en una fuerza prescriptiva que buscaba el disciplinamiento de las mujeres cocineras (Giard, 2006, t. 2, p. 155).

Asimismo, para resolver el problema del valor de las recetas, vuelve a resultarnos sugerente el aporte de Richard Sennett (2009). Este último entiende que el hacer involucra, más que prácticas ciegas e irreflexivas, formas de conocer y de apropiarse de los objetos que devuelven saberes sólidos y necesarios. Por ello mismo, el saber-hacer no demora en convertirse en "rece-

\section{(이요 $(3$}


tas", expresadas en forma oral pero también escrita. Fundamentalmente, es en la gimnasia de escritura de las prácticas donde podemos mensurar con mayor precisión las características del conocimiento práctico. Es decir, interpretar el contenido, la forma, la especificidad, los sujetos que involucra, los sentidos que pretende transformar. A la vez, el éxito o fracaso de cada receta escrita dependerá de la forma en que se instituya en ellas el conocimiento. La prosa que distingue a la buena receta es aquella que, por un lado, en lugar de explicar e interpretar, nos muestra con precisión las secuencias del hacer $y$, por otro, entabla un vínculo empático entre el(la) que informa y los(as) receptores(as). Ya sea valiéndose de recuerdos, de metáforas, de anécdotas, de consejos, etc., los(as) autores(as) de recetas ilustran por medio de palabras el orden de los procesos prácticos (Sennett, 2009). Asimismo, el lugar asignado a la imaginación en el lenguaje de la acción es crucial para efectivizar el trabajo de los(as) lectores(as).

Corolario. El saber culinario se inscribe en el registro de las artes de hacer. Estas, lejos de ser ingenuas y espontáneas, se plasman a partir de un recorte consciente y cargado de sentidos éticos, cognitivos, políticos, estéticos y morales particulares. Quienes cocinan saben lo que hacen, y negocian un lugar para su saber. A la vez, el saber-hacer, a los efectos de reproducirse y conservarse, muta en recetas amparadas por la oralidad pero también por la escritura. Escribir una receta implica un movimiento intelectual que va de la acción a la palabra oral, y de esta a la escritura. Sin duda, esta dinámica habilita una cadena de pasos, auxiliados por elementos diferentes y de naturaleza disímil, que pueden ser resueltos por una misma persona o por varias con el propósito de evitar los dramas de la paradoja del omnívoro. Por ser omnívoro, el género humano puede consumir una infinidad de alimentos, pero esa amplitud electiva tiene un límite, la necesidad de la variación en la dieta. Es por ello que la libertad del comensal humano necesita fijar fórmulas para lograr así la correcta alimentación. En este punto es donde irrumpe la receta culinaria. De tal modo, cada cultura, con un gesto entre temeroso y entusiasta, se encargó de establecer las recetas alimentarias apropiadas para la conservación de la salud y de la vida. Innovar en materia culinaria fue un gesto bifronte: por un lado, abre el fascinante mundo de los sabores, los gustos, los aromas, las texturas desconocidas; pero, por otro, habilitó la posibilidad de la muerte provocada por la ingesta de lo tóxico, del veneno y demás sustancias nocivas para el organismo (Fischler, 1995). En consecuencia, no obstante la percepción general, cocinar fue y es una de las actividades cotidianas menos espontáneas. Es decir, con el fin de cuidar la vida, existie-

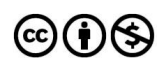


ron y existen fórmulas culinarias que reglamentan las prácticas; ellas son las famosas recetas con sus dos custodios: la voz y la escritura.

Las recetas son textos que intentan hacer cosas con las palabras. Sus efectos performativos, aunque apuntan al(la) lector(a), no demoran en impactar sobre las(os) autoras(es) (Austin, 1998). Justamente, este artículo recupera la problemática de la escritura del saber culinario y sitúa como eje de discusión el momento en que irrumpieron las mujeres como autoras. Como ya dijimos, la magnitud de esta temática será auscultada en el marco de las páginas de la revista Damas y Damitas. A los efectos de ordenar nuestro análisis, lo dividiremos en tres partes. En la primera exponemos una síntesis de las principales características de la revista. En la segunda, nos adentramos en el estudio específico de las recetas de cocina de Julia E. Bourdieu, ponderando sus colaboraciones en las páginas de la revista con el surgimiento de las clases prácticas dadas por la misma profesora en la escuela femenina auspiciada por la casa editorial. Finalmente, cerramos el análisis incorporando el aporte que las empresas de productos alimenticios hicieron al contenido del semanario. Un aporte que se evalúa no sólo en términos de auspicios económicos, sino también en su carácter de oferente de recetas de cocina. Entendemos que, en la bisagra de las décadas de 1930 y 1940, el saber culinario, hogareño y doméstico adquirió dos características: por un lado, la marca del mercado y de la sociedad de consumo; por otro, el nombre de mujer que garantizó la calidad de las recetas.

\section{RECIBA LOS MIÉRCOLES A DAMAS Y DAMITAS, UNA AMIGA QUE LLEGA}

Damas y Damitas fue un semanario que, desde el 5 de julio de 1939, se incorporó al creciente mercado editorial destinado al público femenino. ${ }^{2} \mathrm{Ya}$ desde el título se describía el perfil de las lectoras. Con la expresión "damas" se aludía a las señoras maduras, casadas o viudas, madres, y, con el vocablo "damitas", a las jóvenes solteras en la antesala del matrimonio. De este modo, exceptuando a las niñas, las mujeres encontraban un espacio de lectura exclusivo. El denominador común de la publicación era el interés por la moda y las noticias en el plano del vestuario, de los cosméticos, del mundo del cine

${ }^{2}$ Para ampliar el tema en el caso argentino se recomienda: Bontempo (2012); Caldo (2013a).

\section{(ㅇ)(1) $(9$}


y del espectáculo, pero también en lo relativo a los quehaceres domésticos: el cuidado del hogar, las labores de punto, la maternidad y, entre todo esto, el saber culinario. En la primera página de cada número, a modo de subtítulo o consigna, decía: "Reciba los miércoles a Damas y Damitas con la alegría de una buena amiga que llega". ${ }^{3}$ Así, la revista irrumpía como "una amiga" experta que venía a traer novedades, adelantos y saberes propios del acontecer femenino. Pese a que el editor e ideólogo fue un varón, Emilio Ramírez, ${ }^{4}$ la revista se dirigió al género femenino y asumió la voz de las mujeres (o al menos la mayoría de las notas estaban firmadas con nombre femenino) para interpelar a las lectoras. Se explica que el editor-director responsable tuvo a bien seleccionar colaboradoras que escribían o asesoraban en las distintas notas, artículos y columnas. En consecuencia, las páginas del semanario llevaron la firma de algunas profesoras de economía doméstica, gastronomía, corte y confección, moda, estética y belleza, pero también de otras(os) que, muchas veces bajo seudónimos, aportaron tanto sus relatos literarios como también las notas relacionadas con el mundo del cine y de la radio (Batticuore, 2005). Finalmente, en medio de tantas autoras, aparecieron los varones aportando sus saberes en las secciones de puericultura y consejos médicos (Nari, 1995).

Los conocimientos vertidos por estos(as) especialistas estuvieron, muchas veces, basados en las inquietudes que las lectoras explicitaban en sus cartas. En Damas y Damitas el intercambio epistolar entre editorial y seguidoras fue el disparador del contenido. Algunas secciones fijas se construyeron exclusivamente a partir de las consultas planteadas en las epístolas recibidas. ${ }^{5}$ Incluso ciertas notas fueron presentadas siguiendo el formato de escritura de la carta. ${ }^{6}$ No es casual que una revista dirigida a las muje-

3 Damas y Damitas, núm. 71, 6 de noviembre de 1940, p. 1.

${ }^{4}$ Emilio Ramírez (1901-1960) emigró a la Argentina a temprana edad y pasó su vida en la ciudad de Buenos Aires. Se dedicó al mundo del periodismo y de la fotografía. Dio sus primeros pasos profesionales en diarios como Crítica, La Razón y Noticias Gráficas, para luego afrontar, en el año 1939, un proyecto editorial que llevaría su nombre: Emilio Ramírez Ediciones. Uno de los primeros productos de esta imprenta-editora fue, justamente, Damas y Damitas, una revista destinada al público femenino. A esta le seguirían Vea y Lea (publicación de interés general), Destinos, Maniquí, Rosicler, entre otras (Ulanovsky, 2005).

${ }^{5}$ Por ejemplo, el contenido de las secciones: "Buzón del magisterio", "Si usted me aconsejara" y "Astrología" eran, fundamentalmente, respuestas a las preguntas e inquietudes de las lectoras. En forma de respuestas a las preguntas de las lectoras se estructuraron casi todas las secciones del semanario.

${ }^{6}$ Con el correr del tiempo comenzaron a publicarse algunas notas escritas en forma de cartas: "Cartas de Mar del Plata", "Cartas a una elegante" y "El sermón de la abuela".

\section{(이요 $(2$}


res y con pretensiones de llegar a todos los puntos del país, ampliando así el círculo de lectoras, apelase al género epistolar como forma de exponer los contenidos. Precisamente, la carta fue el modo de escritura privada e íntima que la modernidad habilitó para la feminidad. Las reglas de la urbanidad supervisaron esos escritos íntimos que permitieron a las damas instalarse en el espacio público a través de la letra escrita. ${ }^{7}$

Asimismo, del cruce de preguntas y respuestas se infirieron los alcances de la publicación. Como era de suponerse, la mayoría de las cartas de lectoras provinieron, en primer lugar, de ciudades como Buenos Aires, Rosario y Córdoba, y luego de otras capitales y urbes importantes como Mendoza (Mendoza), San Fernando del Valle de Catamarca (Catamarca), Resistencia (Chaco), Santiago del Estero (Santiago del Estero), Santa Fe (Santa Fe), San Miguel de Tucumán (Tucumán), San Juan (San Juan), Formosa (Formosa) y La Plata (Buenos Aires). Pero también se hicieron presentes mujeres residentes en centros urbanos menores emplazados en diferentes provincias. Así, encontramos correspondencia situada en San Nicolás, Pergamino, Lanús, Junín, Chascomús, Tandil, Azul, Mar del Plata, Bahía Blanca, Trenque Lauquen (prov. de Buenos Aires); Esquina, Goya (prov. de Corrientes); Rafaela, Moisés Ville, Casilda, Tostado, Vera, Villa Constitución (prov. de Santa Fe); Paraná, Concordia, Victoria, Villaguay (prov. de Entre Ríos); Cruz del Eje, Inriville (prov. de Córdoba); General Acha, Santa Rosa (territorio nacional de La Pampa); Charata (prov. de Chaco) o La Quiaca (prov. de Jujuy). Además existieron remitentes de urbes situadas en países limítrofes: Montevideo (Uruguay) y Sucre (Bolivia). El listado de ciudades dejó constancia de la cobertura espacial alcanzada por la publicación.

Semanalmente y tanto desde ciudades capitales como desde poblaciones menores, las mujeres intentaban saciar sus dudas, necesidades y demandas de saber en las páginas escritas por las expertas colaboradoras de la revista. Algo punzaba en el imaginario de las amas de casa, obligándolas a requerir la ayuda de los(as) especialistas en materia de trabajos del hogar,

${ }^{7}$ La problemática del género epistolar ha sido ampliamente tratada en el libro referenciado: Bouvet (2006). Asimismo, Roger Chartier (1994) analizó los secretarios en su triple acepción, como libros modélicos para escribir cartas, como persona que las escribía pero también como el espacio de tal acto. Una vez abordada la carta como género pero también como práctica social situada, nos sirvió leer las palabras de Isabel Morant (2006), quien, analizando el corpus de fuentes para realizar la historia de las mujeres, incorporó la carta con las siguientes palabras: "el género epistolar, que sabemos que en un determinado momento dominarían las mujeres" (t. 1, p. 11).

\section{()(1) $\$$}


y la revista apuntó a satisfacer tal demanda. El medio de comunicación fue el correo. Las misivas, recuperadas en cada edición, eran el soporte del intercambio cognitivo, pero también del mismo acto de comprar la revista. Las lectoras de Damas y Damitas, lejos de ir a la librería, hacían su pedido por vía del correo. El acceso era por suscripción semestral o anual y se solicitaba enviando a las direcciones sugeridas el cupón de compra impreso en la misma publicación. A la vez, para incrementar el número de suscritas, la editorial lanzaba promociones que consistían en abaratar costos o en la promesa de obsequios. ${ }^{8}$

Aunque nunca superó las 75 páginas y con una calidad limitada en el papel, en la encuadernación y en la reproducción de imágenes, el semanario de Emilio Ramírez irrumpió en el mercado editorial con la misma línea temática que revistas como El Hogar (1904), Para Ti (1922) o Maribel (1932). Pero las seguidoras de Damas y Damitas no eran las señoras de las clases pudientes y acomodadas urbanas, sino las mujeres de sectores medios residentes en la ciudad pero fundamentalmente en urbes de distintas dimensiones del interior del país. Estas últimas utilizaron las revistas como referentes de consulta para resolver los interrogantes surgidos en el devenir de la vida cotidiana del hogar. Dijimos que, pese a ser un producto modesto, Damas y Damitas recuperó tópicos temáticos y sentidos ideológicos en cuanto a quehaceres domésticos y cuestiones femeninas que trataban sus competidoras. De este modo, el mercado editorial logró un sistema de complementariedad a partir del cual la fuerza performativa del género, con relación a la consolidación de la mujer doméstica, amplió su incidencia hacia otros sectores sociales. ${ }^{9}$ Entonces, en las páginas de esta publicación las señoras de menores recursos se enteraban de la moda pero también de los eventos sociales y de adelantos en materia de cuidados y confort del hogar que utilizaban sus congéneres pertenecientes a los sectores sociales más encumbrados. Justamente, los costos bajos, la propensión al ahorro, los consejos de reciclaje de materiales y la interpelación a una lectora protagonista de las labores domésticas dan cuenta de la singularidad social de las lectoras de Damas y Damitas. Estas debían sortear con

${ }^{8}$ Por ejemplo, en el núm. 70 se dedicó una página completa al siguiente anuncio: "Lectora, ¡Suscríbase! DAMAS Y DAMITAS inicia su primera conscripción de suscriptoras, por cinco peSOS. LE OFRECE: ABSOLUTAMENTE GRATIS MOLDES, UNO PARA CADA ESTACION DEL AÑO DEL TALLE QUE USTED DESEE... TODO POR \$ 5 ANUALES. Llene el cupón y envíelo con CINCO PESOS en giros, bonos postales o cheque, a la administración de DAMAS Y DAMITAs". Damas y Damitas, núm. 70, 30 de octubre de 1940, Buenos Aires, p. 63 (Conservamos los resaltados del original).

9 La noción de "performatividad del género" está tomada de Butler (2001).

\section{(ㅇ)(1) $\$$}


poco dinero, con manos propias y muchas veces desde contextos rurales o pequeñas poblaciones donde el consumo era reducido a pocos comercios y por catálogo, los avatares de la vida femenina asignada a la mujer doméstica.

El contenido entregado a las lectoras estuvo ordenado por un índice temático expuesto en la primera página de cada número. A grandes rasgos, cada entrega trabajó sobre cuatro ejes fijos: la literatura, que lograba la distensión y la ensoñación de las seguidoras; las sugerencias y prescripciones para las actuales o futuras amas de casa; los temas vinculados con la moda en el vestuario, donde se respetaron criterios como las estaciones del año, los eventos en la vida de mujer (casamientos, aniversarios, cumpleaños), así como la religión (la moda para ir a misa), y, finalmente, los artículos que rescataban el acontecer de las estrellas del cine y de la radio, junto a la recomendación de audiciones o películas.

En su estructura interna la revista tuvo algunas notas móviles que podían comprender temas de moda, belleza, labores, así como también los clásicos cuentos o novelas breves; junto a otras fijas que se reiteraban semanalmente incluso unificadas por el nombre del(a) autor(a). El índice condensó la agenda de temas relevantes para una mujer que, desde la juventud hasta la vejez, situó como objeto de su vida el matrimonio y la maternidad. Así, jovencitas, señoras maduras y abuelas intercambian sus consejos y saberes en las distintas secciones. Las mujeres, desde su más tierna infancia, proyectaban para el futuro ser "dueñas de casa". De tal forma, la cotidianidad femenina se veía alterada en el pasaje del hogar paterno al conyugal. Ellas seguían haciendo las mismas actividades, aprendiendo las mismas cosas y sometidas bajo poderes, aunque no iguales, similares (del padre al marido). Por lo tanto, la joven esposa debía llegar a comprender los defectos, problemas y dificultades del esposo. Su deber era ser, ante todo, una fiel y buena compañera.

El fin último de las vidas femeninas era el matrimonio, y para ello debían entrenarse en una serie de actividades. Esos quehaceres no estaban inscritos en la feminidad, sino que había que construirlos. Con tal propósito se desplegó un arco de conocimientos que comprendieron desde la puericultura hasta la economía doméstica. En este proceso fueron diferenciándose dos cuestiones.

La primera, en medio de una sociedad donde el discurso de la ciencia alcanzaba, colonizaba y nombraba todas las prácticas, cuerpos, lugares y acciones posibles, el género femenino adquirió una semántica específica. Pero el arco de saberes que interpeló a la mujer fue víctima de una paulatina segmentación que no demoró en redundar en connotaciones de género. Así,

\section{(이요 $\$$}


mientras los varones asumieron la investigación, práctica y difusión de temas como la puericultura, la obstetricia y la ginecología, las mujeres fueron conquistando el espacio de elaboración de los saberes propios de la economía doméstica. El siglo xx se inauguró con una serie de mujeres que, personalmente o por medio de sus escritos, educaban a otras mujeres en temas relacionados con los quehaceres domésticos (Caldo, 2009; Nari, 1995, 2004).

La segunda, la semántica que dio realidad a estas disciplinas fue impuesta desde arriba. Esto es, la educación de la mujer burguesa se dispuso como eje para la formación integral de las mujeres. Sin duda, las condiciones materiales que envolvieron la vida cotidiana de los sectores populares obstaculizaron la plasmación directa de dichos mandatos. Habrá que esperar el avance del siglo xx y su consecuente democratización de la comodidad, para percibir la cristalización de las directivas decimonónicas. ${ }^{10}$ Asimismo, los soportes de la transmisión de los saberes del sexo femenino y de la economía doméstica fueron, en sus comienzos, objetos costosos (libros de autores locales, traducciones o incluso textos en otros idiomas). Por ello, suponemos que el agente democratizador de dichos conocimientos fue la escuela pública, así como los hospitales, lactarios, bibliotecas populares y productos editoriales de costos menores, entre los cuales se listan publicaciones como Damas y Damitas (Gutiérrez y Romero, 1995; Nari, 2004).

En este marco fue adquiriendo especificidad el campo de la economía doméstica. Este resultó ser un gran receptáculo donde se concentró una multiplicidad de prácticas y reglamentaciones. El carácter misceláneo de la disciplina repercutió hasta en su denominación. Y aunque muchos fueron los debates alrededor del nombre, se impuso el de economía doméstica (Caldo, 2012). Este rótulo, compuesto por dos vocablos griegos: oikos -casa- y nomía -gobierno-, aludió a un conjunto de conocimientos que la ciencia económica des-preció. ${ }^{11}$ Se trató de los atinentes a la administración, financiamiento y gobierno del hogar. Así, residuo de la economía, la economía doméstica recayó dentro del conjunto de discursos destinados a in-formar a la mujer moderna.

${ }^{10}$ El concepto de democratización de la comodidad lo hemos encontrado trabajado por el historiador Peter Gay (1992) para la sociedad victoriana del siglo xix y también por Inés Pérez (2012) para la realidad argentina, puntualmente Mar del Plata en la segunda mitad del siglo xx.

${ }^{11}$ Escribir "des-preció" implica un planteo doble: por un lado, que la economía como tal invalidó los saberes propios de la administración del hogar, y, por otro, esa misma invalidación llevó a quitarles su precio (salario) como trabajo digno de remuneración (Liernur, 1997, p. 8).

\section{(ㅇ)(1) $\$$}


Empero, el siglo xx traerá consigo el abandono del término economía doméstica en beneficio del de ciencia doméstica. La voluntad de saber de la época hizo extensivo el discurso científico al ámbito doméstico y en tal sentido presenta su disciplina: "La ciencia doméstica es el conjunto de preceptos y de prácticas conducentes al buen gobierno, administración e higiene de una casa, a la conservación de la salud de la familia, a la crianza, dirección y educación de los hijos, a la felicidad y al bienestar del hogar" (Bassi, 1920, pp. 1, 2).

En realidad, la veta innovadora del concepto residía en el modo de entender el conocimiento producido. Esto es, los saberes del hogar ya no eran entendidos como arte sino como ciencia. Esta última categoría había sido utilizada por tratadistas como Appleton (Liernur, 1997, p. 23) o en publicaciones como El Monitor de la Educación Común. ${ }^{12}$ Entonces, la ahora reconocida ciencia fue presentada como un conjunto de teorías y sus consiguientes aplicaciones, que la mujer del naciente siglo xx debía conocer, comprender y ejercitar. La idea era lograr que la mujer se destacase en el gobierno y la administración de la casa a partir de los principios del ahorro, la higiene y la moral. En consecuencia, bajo el gran paraguas de la ciencia doméstica, las niñas aprenderían contabilidad doméstica; preceptos para elegir una buena vivienda, tanto para alquilarla como para comprarla ya construida o para construirla; limpieza, higiene y ornamentación del hogar; atención al personal doméstico; cocina y alimentación; el vestido de la familia; selección y atención de animales domésticos y control de plagas; nociones de jardinería.

\section{JULIA E. BOURDIEU, ECÓNOMA Y EDUCADORA}

Dentro del conjunto de saberes que desplegó la ciencia doméstica, la cocina fue adquiriendo paulatina relevancia hasta colonizarla por completo. Es preciso aclarar que, al tiempo que los manuales y tratados de educación femenina asumieron la transmisión del saber culinario preferentemente orientado a las mujeres cocineras, los recetarios de cocina específicos, editados en la época, desconocieron el vínculo con la ciencia doméstica, presentándose así como producto de la gastronomía o, en su defecto, del arte culinario o de la pericia sibarita. Asimismo, revistas femeninas, como Para Ti o El Hogar, dividieron las indicaciones generales para el cuidado, la higiene y la economía

\footnotetext{
${ }^{12}$ Por ejemplo en El Monitor de la Educación Común, núm. 470, 29 de febrero de 1912, p. 279.
}

\section{(이요 $\$$}


del hogar de las otras vinculadas con el menú, con el placer de comer, con la estética culinaria y con las recetas de cocina. ${ }^{13}$ Pero, en el ocaso de los años treinta (1939), Damas y Damitas expuso una sección exclusiva de economía doméstica en cuyo contenido solamente se registraron recetas culinarias e indicaciones generales para la mesa y para cocinar.

Entre los años 1939 y 1942 la sección se denominó "Curso de economía doméstica", y su contenido tuvo dos características estables: una de ellas fue la marca del aceite Cocinero como auspicio exclusivo; la otra, el nombre de la profesora a cargo. Semanalmente se transcribió una serie de recetas elaboradas y probadas por la profesora Julia Elena Bourdieu. La experta en cuestión, también llamada ecónoma,${ }^{14}$ ordenó sus presentaciones con las siguientes características:

Las recetas formaban parte de la colección de Julia E Bourdieu. De este modo, en cada nueva edición de la revista las lecciones culinarias aparecían numeradas.

En cada edición se presentó un menú que ofició de índice de las recetas expuestas. El mismo contó con una combinación de platos salados y otros dulces destinados al servicio completo de una comida (almuerzo o cena).

Debajo de las recetas se incluyó el subtítulo: "Consejos experimentados en la práctica”, donde se describieron sugerencias para servir la mesa, para conducir e instruir al personal doméstico y también para llevar adelante la práctica culinaria concreta.

Algunas de las recetas llevaron impreso y entre paréntesis el nombre y el lugar de origen de las lectoras que las solicitaban.

En el pie de página de cada edición se publicó una historieta denominada: "El cocinero y su sombra", con el auspicio de la firma: Cocinero. Pese a ello, los textos que narraban las recetas de Julia Bourdieu no incluyeron marcas comerciales. La ecónoma enunciaba los ingredientes utilizando los nombres genéricos.

De Julia E. Bourdieu conocimos su rostro retratado en una fotografía que acompañaba cada edición y su profesión: profesora de economía doméstica. También supimos que mantuvo un fluido intercambio epistolar con sus lectoras. Por ejemplo, el menú compuesto por Turrón de mazapán de al-

${ }^{13}$ Si bien excede la propuesta de este artículo, es preciso aclarar que la gastronomía o la cocina tendente al buen comer y al placer reposó en manos de cocineros y expertos en la temática que fueron preferentemente varones. Al respecto véase Caldo (2013b), Revel (1996).

${ }^{14}$ En torno a la figura de las ecónomas en la Argentina de los años treinta pueden consultarse Caldo (2013a), Pite (2013).

\section{(이요 $(3$}


mendras, Turrón de almendras, Costillas a la Villeroy y Tallarines verdes había sido solicitado por la señorita G. Notigemar Sanford $;^{15}$ o el Budín de coliflor, que fue requerido por Coca de Liniers. ${ }^{16}$ Así, semanalmente y a pedido, la profesora disponía una variedad de platos para resolver la demanda de sus seguidoras.

Concretamente, la exposición de las recetas fue prescriptiva, a partir de una prosa que fragmentó ingredientes y procedimientos.

\section{EMPANADAS CRIOLLAS}

(A pedido de Isabel L. de Iviglia, de Santa Rosa).

Ingredientes: $1 / 2 \mathrm{~kg}$ de harina, 1 cucharada de vinagre $\mathrm{y}^{1 / 2}$ de aceite, sal, $1 / 2$ taza de grasa derretida y tibia, 1 taza de agua templada.

Relleno: $3 / 4 \mathrm{~kg}$ de carnaza de cuadril, 2 cebollas grandes, 1 tomate, 2 cucharadas de pasas de uva, aceitunas verdes, 1 cucharada grande de pimentón, sal, 2 huevos duros, pimienta, 1 cucharada grande de azúcar, tomillo, un poquito de comino, 1 taza de aceite, 1 hoja de laurel. Varios: grasa de vaca y azúcar molida.

Preparación del relleno: picar la cebolla no muy finita, freírla en aceite con ajo picado, el laurel y tomillo, y una vez doradita, el tomate picado al rato y agregarle la carne picada en la maquinita. Cuando se nota algo cocida, añadirle las pasas, las aceitunas, la sal, pimienta, azúcar. Dejar cocinar unos minutos, disolver el pimentón en un poco de caldo y agregarle a la preparación; añadir el comino y el perejil picado; cocinar hasta que se note la salsa espesita; dejar enfriar, agregándole los huevos duros cortados en pedacitos.

Masa. Preparación: colocar en un tazón la harina, hacer un hoyo en el centro, agregar la grasa, el agua con sal, uniendo con una cuchara hasta formar una masa ni dura ni blanda; antes de terminar de unirla, añadirle el aceite y el vinagre batiendo con un tenedor (esta masa no debe trabajarse mucho); dejar reposar 10 minutos, dejándola medianamente fina, untar con grasa, espolvorear con harina, doblarla por la mitad, untar nuevamente con grasa, espolvorear harina, volver a hacer la operación otra vez; luego se estira, no muy finita; se cortan unos medallones del tamaño que se desee; se coloca un poco de relleno en cada uno y se cierran, haciéndoles un repulgue. Se

15 Damas y Damitas, núm. 70, 30 de octubre de 1940, pp. 58-59.

16 Damas y Damitas, núm. 102, 11 de julio de 1941, pp. 58-59.

\section{(ㅇ)(1) $(9$}


fríen en abundante grasa caliente, luego se escurren sobre papel blanco y se espolvorean con azúcar molida. ${ }^{17}$

Escribir la receta de las empanadas es y fue un ejercicio difícil puesto que el proceso de preparación llevó y lleva, al menos, tres pasos: la elaboración del relleno, la de la masa y, finalmente, la conjunción entre ambos para dar forma al producto final. Respetuosa de tales dificultades, Julia Bourdieu fragmentó en cuatro partes la exposición de la fórmula: ingredientes para la masa y para el relleno y los procedimientos para resolver ambas instancias.

En cuanto al estilo en la escritura las recetas se expresaron a través de un encadenamiento de verbos en infinitivo (picar, cocinar, añadir, colocar, espolvorear, reposar). La ausencia del "yo" en la enunciación otorgó rigor y objetividad a la fórmula. Con respecto a la exposición de los ingredientes y los procedimientos, fueron unificados los pesos y medidas (patrón métrico decimal) y no se enunciaron marcas comerciales. Los tiempos de cocción se esbozaron rigurosamente y se apeló a una serie de utensilios de cocina como la máquina picadora de carne y elementos como tenedores, cucharas, etc. Las técnicas implementadas parecieron desconocer la aplicación de la energía eléctrica; aún seguía siendo el trabajo y la fuerza corporal de la cocinera el principal motor de la acción culinaria.

Desde el 5 de julio de 1939, día en que apareció esta pequeña revista, hemos venido cumpliendo al pie de la letra lo prometido. Lo decimos con honda satisfacción de haber respondido en todo a la confianza y a la simpatía que la mujer argentina había depositado en estas páginas y en esta casa, que desde el primer momento fue suya.

DAMAS Y DAMITAS prometió ser mucho más que lo que era el día de su aparición, y poco a poco ha ido escalonando los peldaños que con el tiempo tenían que convertirla en la revista preferida de la mujer. Sobrevinieron las dificultades de la guerra, y esta revista, superando todos sus esfuerzos anteriores, aumentó de tamaño, mantuvo la misma calidad de material en sus páginas, engalanó estas con delicados colores y continuó y continuará manteniendo siempre su precio inicial. ${ }^{18}$

17 Damas y Damitas, núm. 108, 23 de julio de 1941, pp. 52-53.

18 Damas y Damitas, núm. 149, 6 de mayo de 1942, pp. 4 y 5.

\section{(이)(1)}


En el año 1942, la sección culinaria dejó de llamarse "Curso de economía doméstica" y adquirió el título de "Para las amas de casa". Las recetas siguieron siendo responsabilidad de Julia Bourdieu y, por ende, conservaron el estilo habitual. Sin embargo, el nuevo formato imprimió algunos cambios: se redujo el número de recetas y el eje temático comenzó a residir ya no en el menú, sino algunas veces en los ingredientes, otras en conmemoraciones (se privilegiaron, fundamentalmente, las fechas religiosas) o en los cambios de estaciones (en las vísperas de la primavera se expusieron platos dulces alusivos, en tanto que en el invierno subía el potencial calórico de las sugerencias culinarias).

Por ejemplo, en abril de 1942 se promocionó el uso del maíz como ingrediente culinario más allá de su injerencia en los platos considerados tradiciones nacionales (mazamorra, locro, etc.). De este modo, Julia Bourdieu abrió la exposición de sus recetas con el siguiente texto de carácter explicativo:

MAíz. El hecho de que nosotros comamos tan poco maíz, teniendo tanto, quiere decir que la única razón que existe es que se ignora entre las familias la forma de cocinarlo. En América, y sobre todo en Argentina, en otros tiempos era el maíz casi una comida de rigor; hoy únicamente las provincias del norte y las andinas mantienen esa tradición. Buenos Aires se sirve de él en forma reducida, cosa que es de lamentar por ser un alimento que se cosecha abundantemente, que es de gran valor nutritivo y de escaso valor monetario; esto se aprecia con sólo saber que el kilo de harina de maíz cuesta \$ 0.07 en cualquier almacén, y el maíz en grano de $\$ 0.03$ a $\$ 0.04$ el kilo.

Hoy por hoy, Estados Unidos es una de las naciones que consume más cantidad de maíz en la cocina. Nosotros, aparte de los locros, humitas y mazamorras, conocemos pocas fórmulas para cocinarlo. Por eso en este número y en el próximo les doy recetas para platos ricos a base de maíz. ${ }^{19}$

En la cita, la autora interpeló directamente a las lectoras. Es decir, después de la fundamentación aseguró que ella iba a transcribir los posibles usos del maíz. Así, describió las recetas de Polenta en fuente y Suspiros en salsa madera, prometiendo exponer fórmulas nuevas en los números siguientes. Al presentar las recetas, la forma de la escritura retomó su estilo convencional: ingredientes separados de los procedimientos, el empleo de los verbos en infinitivo, el sujeto de la acción enunciado en tercera persona y todas las

19 Damas y Damitas, núm. 145, 8 de abril de 1942, p. 65.

\section{()(1) $\$$}


marcas de un estilo al que Julia tenía acostumbradas a sus seguidoras. Curiosamente, la profesora Bourdieu destacó la importancia del maíz por la abundancia de su producción nacional y también por el frecuente empleo que se hacía de él en la cocina estadunidense. Pero en ningún momento aludió a las tradiciones prehispánicas vinculadas al producto; por el contrario, ella quería superar la tendencia que asociaba el maíz a un corpus de platos fijos y costumbristas. Aunque la cocina de Julia fue variada, sus comidas fueron preferentemente saladas. Por ejemplo, ella propuso arrollado fiambre, escalopines al jugo, budín de coliflor, masitas de frutas, chupín, tartaletas de langostinos, panqueques de dulce, jarabe de ciruelas (refresco), canelones a la Rossini, papas Julie con bifes, pasteles de hojaldre fritos, dulce de tomates, gallina deshuesada rellena, empanadas criollas, bocadillos de batata o arrolladito de dulce de leche, tortilla dulce con frutas, lomitos Jeanine, lomo en salsa de nuez, masa de hojaldre para horno, zapallitos a la española, paleta de cordero rellena, tarta de manzanas, naranjas rellenas, croquetas de París, rosas de jamón, gateau primavera, arroz a la española, cestos de rosas, fondant, budín de amarettis.

Sin duda, la propuesta de Julia, al tiempo que evadió la culinaria prehispánica y tradicional, estuvo inscrita en una gramática culinaria ecléctica (Fischler, 1995). En ella las sugerencias francesas se mezclaron con las empanadas criollas (fritas en grasa) y con los bocaditos de batata. Además, las recetas intentaban saciar las demandas de las comidas (almuerzo y cena), dejando en un lugar menor a las propias de los tés, meriendas, desayunos y demás encuentros de degustación de dulces.

Lo interesante de la propuesta culinaria de Damas y Damitas fue que, en paralelo con la transmisión escrita de dicho saber, se presentó la promoción de las clases de cocina que la misma Bourdieu dictaba en el marco de los cursos para la educación de la mujer auspiciados por la revista. Justamente, el número 149 del mes de mayo de 1942 se abría con la siguiente noticia:

Se inauguraron los cursos prácticos de cocina

Con un éxito sin precedentes, se inauguró en la fecha prevista nuestro salón de actos, en el que se dictan actualmente los cursos prácticos de cocina a cargo del chef Sigmund Czala y la profesora Julia Elena Bourdieu.

Al acto de la inauguración asistieron representaciones de las más importantes firmas anunciadoras de esta Capital, personificadas en los jefes de propagandas [...] El 5 de noviembre del pasado año, superando no ya su propio esfuerzo sino el de todas las revistas similares del continente, inauguró su

\section{(이요 $(2$}


Instituto Superior de Enseñanza Femenina por Correspondencia, magnífica obra social auspiciada por primera vez por una empresa periodística. Amplia y fervorosa fue la adhesión de la mujer sudamericana a esta iniciativa nuestra. Hoy suman docenas de miles las mujeres que estudian y se labran un porvenir gratuitamente en nuestra casa. Y como broche final se ha inaugurado ahora nuestro salón de actos, y en él los CURSOS PRÁCTICOS DE COCINA, a cargo de un gran chef europeo y de una prestigiosa profesora argentina. ${ }^{20}$

La revista dio un salto que trascendió la transmisión escrita del saber culinario, donde sólo se reconocía el nombre de la experta, dando lugar así a la voz de las mujeres lectoras y aprendices. Para ello, primero apeló al intercambio epistolar, del cual la profesora Julia dejó constancia en cada una de sus recetas con la expresión "a pedido de". Pero finalmente creó su instituto para educar a las mujeres con un salón exclusivo destinado a clases y conferencias. Desde entonces, todas las semanas, junto a las recetas de Bourdieu se publicaron "Noticias del Instituto Superior de Enseñanza Femenina". En este apartado se comunicaron fechas de encuentros, los cupones para solicitar la participación en las clases, sorteos de cursos y promociones de conferencias. También se expresaron cuestiones vinculadas a los costos de inscripción y a los franqueos que debían pagar por el intercambio de materiales (de estudio y evaluaciones). En casi todos los números se publicaron, además de los cupones de inscripción, invitaciones como la siguiente: "CONCURRA USTED TAMBIÉn a las clases de ARTE CULINARIo que dicta todos los martes la profesora Julia Bourdieu. Los cursos son de enseñanza práctica, con intervención de las alumnas, y en ellos se dictan también clases especiales de COCINA PARA ENFERMos, de máxima utilidad para la mujer. Asista a estos cursos presentando el cupón que aparece en esta misma página." ${ }^{21}$

El editor se atribuyó la originalidad de haber sido quien, por primera vez, financió desde un emprendimiento editorial un instituto formativo para las mujeres. Pese a los dichos de Ramírez, sabemos que la revista El Hogar venía haciendo lo mismo desde el año 1930; la única diferencia era que la propuesta de la Editora Haynes no contaba con un local propio. A su vez, El Hogar también publicó en el semanario las principales recetas planteadas en tales clases. Los números de la década de 1930 presentaron las lecciones de la

20 Damas y Damitas, núm. 149, 6 de mayo de 1942, pp. 4 y 5.

21 Damas y Damitas, núm. 256, 24 de mayo de 1944, p. 64.

\section{(ㅇ)(1) $(3$}


"Escuela de economía doméstica de El Hogar", donde se transcribían recetas numeradas y coleccionables. ${ }^{22}$

Bajo el nombre "Arte culinario", Damas y Damitas promocionó sus cursos de cocina. De este modo, la cocina dejó de ser un contenido de la economía doméstica (como se lo enunció entre 1939 y 1941) y adquirió el estatuto de arte culinario. Este hecho contrastó, primero, con el cientificismo general de la época, y, luego, con una sección contigua llamada "Ciencia casera”, donde se prescribían consejos útiles en general, entre los cuales fueron dispuestos algunos trucos culinarios. Las notas dispuestas en la columna científica presentaron "métodos" prácticos para resolver problemas del hogar. Por ejemplo:

Método para cocer arroz: Se pone una sartén con agua hasta sus tres cuartas partes; cuando el agua está hirviendo, se le va echando el arroz muy despacio, para evitar que la temperatura del agua disminuya. Se hace hervir fuerte exactamente trece minutos, y luego, rápidamente, se vierte el contenido de la sartén en un colador; cuando el agua caliente se ha escurrido, se le hace correr agua fría de la canilla, por un momento, sacudiendo bien el colador. Esto evitará que los granos de arroz se peguen entre sí; y si se hace esta operación con rapidez, el arroz no se enfría. Algunas personas lo hacen freír con un poco de manteca y es muy rico. ${ }^{23}$

Lo que primaba era la precisión, por caso, en cuanto a la relación entre litros, kilos y los tiempos de cocción. De este modo, se privilegiaba el cómo se cocinaba más que el qué cocinar (como sucedía en el caso de la exposición de recetas).

La ciencia había ingresado a los hogares y las mujeres estuvieron invitadas a resolver sus quehaceres en dicha clave. Así, en las páginas de Damas y Damitas, la ciencia casera, más que aludir a aquellos saberes que se producían en casa, refería a los métodos y procedimientos de intervención práctica del ama de casa. Pero el estatuto del saber culinario dudó en cuanto a cómo llamarse: ¿ciencia o arte? Comparando el modo de escribir y presentar las recetas, vemos que el rótulo fue una cuestión más discursiva

${ }^{22}$ Referencias de lo esbozado en el párrafo pueden encontrarse en El Hogar, núm. 1498, 1 de julio de 1938; El Hogar, núm. 1559, 1 de septiembre de 1939; El Hogar, núm. 1571, 24 de noviembre de 1939.

${ }^{23}$ Damas y Damitas, núm. 70, 30 de octubre de 1940, p. 38.

\section{(이요 $(3$}


que tocante al plano de las prácticas. El siglo xx, y más aún en las décadas de 1930 y 1940, profundizó el cientificismo del hogar. Por ello, se tornó un requisito sine qua non cocinar siguiendo recetas, aplicando métodos, descubriendo las propiedades de los ingredientes para su mejor combinación. Aunque la cocinera, quedando en el camino de la practicidad, no llegó a ser científica, fue interpelada por un conjunto de expertos que la auxiliaron en sus quehaceres.

\section{CUANDO LAS MARCAS "MARCAN" LA CALIDAD CULINARIA}

Pese a la neutralidad comercial que presentaron las recetas culinarias sugeridas por las secciones específicas de la revista, en el paratexto de las distintas páginas se plasmó el aporte ofrecido por las publicidades de diferentes empresas de productos alimenticios.

El naciente mercado en general y el mercado editorial en particular entendieron que la interpelación publicitaria tenía la capacidad de optimizar la creación de demanda. Paulatinamente, los diarios de tirada masiva y también las revistas insistieron cada vez más en el uso de los anuncios comerciales (Saítta, 1998). Pese a los altibajos económicos, con el nuevo siglo esta forma de promocionar los artículos se expandió y los años veinte marcarán el momento de su consolidación definitiva. La marca, con sus eslóganes y consignas, lanzó un guiño de confianza a los(as) consumidores(as). Tal fue la popularidad alcanzada que llegaron a transformarse en sinónimos del nombre genérico de muchos productos, siendo el ejemplo más claro para el rubro alimentario el de la marca de polvos leudantes Royal (Rocchi, 1999, t. II).

No obstante, el auge del consumo tuvo su punto de inflexión en la crisis de 1929. Este acontecimiento representó un momento de caída que, lejos de marcar el fin de la sociedad de consumo, indicó, con la recuperación, su afianzamiento. En el año 1934 el mercado interno se hallaba en plena reactivación. Las empresas, particularmente las del rubro alimenticio, reafirmaron estrategias publicitarias, duplicando su apuesta para renovar el consumo. A la prensa escrita se sumó la radio y, en conjunto, dispararon una multiplicidad de anuncios dirigidos a despertar el interés de los(as) consumidores(as) con discursos que, atendiendo a las diferencias de género, exaltaron el lugar de la mujer. La década de 1930, pese a sus momentos críticos, se inauguró con

\section{(이요 $\circledast$}


la incorporación de agencias publicitarias extranjeras y con un giro estilístico en el ofrecimiento de productos. Si bien a lo largo del periodo 1920-1945 la mujer comenzó a ser blanco de la publicidad, hasta 1930 la oferta incluía productos destinados a la actividad administrativa (máquinas de escribir y de calcular), automóviles y también objetos de recreación (victrolas, radios, etc.). Pero, superada la crisis del 30, el perfil de la oferta exaltó los productos alimentarios, los del rubro de la vestimenta y los artefactos para el hogar (utensilios, máquinas y vajilla, elementos que para su aplicación demandaban, en su mayoría, fuerza manual).

Ahora bien, entre crisis y reactivaciones, a lo largo del periodo 19201945 fue consolidándose la sociedad de consumo y, en su desenvolvimiento, instaló la figura femenina como eje del consumo. Estuviesen o no dedicados a ellas, los avisos comerciales fueron protagonizados por mujeres. Es decir, de la pareja heterosexual, "la figura femenina fue la más utilizada por su atractivo visual y riqueza connotativa, cualidades que son ampliamente explotadas por la estrategia publicitaria" (Ortiz, 2006, t. 5, p. 121). Los papeles de madre, de hija, de novia, de esposa operaron en la clave de la mujer doméstica (Armstrong, 1987) y bajo estas condiciones desfilaron por los anuncios publicitarios. Como afirmó Nancy Cott (1993), la prensa:

No sólo vendía a las mujeres publicidad de los productos ofrecidos, sino también imágenes de sí mismas. Los anunciantes consiguieron imponer los emblemas modernos sobre las prioridades tradicionales de las mujeres. A través de la publicidad, los fabricantes y minoristas de productos para el hogar o para los niños dieron a conocer el concepto moderno de feminidad. Así, a través de la adquisición de bienes, las amas de casa se vincularon cada vez más con la nueva administración doméstica, y la madre, con la crianza científica de los hijos (t. 9, p. 105).

Esta mujer ama de casa advirtió, en la letra de los comerciales, cómo podían incorporarse recursos y materiales novedosos que, fundamentalmente en el rubro de las prácticas culinarias, marcaron un punto de no retorno. Como afirmó el mismo Fernando Rocchi $(1999$, t. 2), superada la crisis del 30 las formas del consumo redundaron en una economía más cerrada, de ingresos bajos, tendente a sustituir importaciones, especialmente en el ramo alimentario. Por ejemplo, las marcas de aceite de girasol y posteriormente de maíz reemplazaron al aceite de oliva tan estimado por los(as) inmigrantes. Precisamente, el aceite provocará largas batallas publicitarias en las páginas

\section{(이요 $(3$}


de la prensa diaria y semanal. Era necesario crear un clima donde los(as) consumidores(as) no dudaran ante la posibilidad de adquirir los productos alumbrados por la industria nacional. Para consolidar estos objetivos era necesario reordenar las formas de consumo y, con ese fin, las mujeres fueron rescatadas como ejes y móviles de la acción.

En este marco, la escena mercantil en la cual la mujer ingresaba a la tienda y solicitaba información al comerciante sobre las virtudes de los productos, debía ser superada por otra donde la misma dama ya conocía de antemano lo que iba a comprar. Ese "saber antes" fue posibilitado gracias a un fino trabajo desplegado por los anuncios publicitarios que, cotidianamente, golpeaban a las puertas del hogar. Tales avisos cruzaron de modo transversal los distintos soportes materiales que interpelaron a la familia en general y a la mujer en particular. Desde los años veinte, las revistas, los diarios, la folletería y los recetarios estuvieron impregnados por las marcas comerciales. Sin duda, el denominador común y el elemento transformador de los distintos soportes de la transmisión escrita del saber culinario fue la publicidad. Esta perspectiva posibilitó, además de la descripción del conjunto de productos alimenticios promocionados, la delimitación del perfil de la consumidora. En otras palabras, el discurso publicitario interpeló con fuerza performativa a las mujeres que leían la prensa en la soledad del hogar. Tal gesto fue ayudado por el juego visual desplegado por la publicidad, pero también por el incremento de los índices de alfabetización (que incluían a las mujeres) y por los cambios en los modos de leer (Llomovatte, 1989). Esto último posibilitó una escena de lectura en la cual la señora, en la intimidad del hogar, leía el diario o alguna revista, ensimismada, en silencio y con la vista. De este modo, las mujeres, mientras leían notas de interés general o específicas para su género, se apropiaban de las novedades en materia de consumo culinario, así como también de las maneras de usar tales productos y sus ventajas, riesgos, etcétera.

En las páginas de Damas y Damitas cristalizan claros ejemplos del proceso que venimos narrando. La revista incorporó numerosos comerciales vinculados con la estética del cuerpo femenino (vestuario, maquillaje o métodos para conservar la figura) o con el hogar (muebles y artefactos), dejando así una franja menor para los alimentos. Entre las marcas de productos alimenticios se destacaron: aceite Gallo, arroz Gallo, aceite Único, aceite Cocinero, frigorífico Armour, Toddy, Confitería del Sur (postres, sándwiches, masas, bombones), manteca Tulipán, aceite Olavina, aceite Ricoltore, bombones Nagell, óleo margarina Swift, café torrado y yerba Águi-

\section{(1)(1) $\$$}


la, Chocofan, aceite La Patrona de Swift, pan Lactal, Maizena, chocolate Noel, Quaker Oats, enlatados La Blanca, yerba mate Napoleón, aceites Las Palmas, entre otras.

Las estrategias de seducción publicitaria presentadas consistieron en concursos, sorteos, intercambios de recetarios y recetas de cocina. Sin embargo, Damas y Damitas, como exponente de la primera mitad de los años cuarenta, mostró dos particularidades: el uso de las historietas y los juegos de preguntas y respuestas.

En el primer caso, fue destacable el auspicio de Cocinero. Todas las semanas publicaba la historieta "El cocinero y su sombra", a partir de la cual la lectora establecía el seguimiento de una secuencia para descubrir similitudes y diferencias entre los dibujos de un varón cocinero que, aunque pretendía evadirse de su profesión vistiéndose de traje y galera, la sombra siempre delataba su oficio. Mientras que Cocinero lanzaba su producto valiéndose de dibujos, la marca Olavina recuperó la figura real del chef de la agencia de cocina Cordon Bleu, Ángel Baldi. Pero el cocinero no estuvo solo, sino que lo acompañó una imagen (fotografía) en la cual dos mujeres dialogaban acerca de las virtudes del aceite:

\section{CAMPAÑA OLAVINA PRO-MEJOR COCINA}

Escenas de la familia feliz, Doña María, la madre y Doña Eulalia, la abuela.

- ¡Por fin puedo cocinar sin humo ni olor! ¡Olavina es realmente maravilloso!

-Y Olavina es el aceite de más cuerpo, por eso resulta tan rendidor y económico. ${ }^{24}$

Esta vez, la palabra autorizada del chef fue refrendada por la propia de las cocineras prácticas y amas de casa. No sólo la madre sino también la abuela avalaron la calidad del producto, activando así la cadena de transmisión familiar. Curiosamente, el comercial no aludió al diálogo entre una madre y una hija (como quizá lo fueron), sino a los papeles de abuela y madre. Estas últimas fueron las protagonistas de muchas de las conversaciones desarrolladas en las cocinas representadas por la publicidad. Las abuelas, emblemas de la experiencia, eran garantes de la virtud de los productos usados, probados y recomendados como parte de la herencia familiar.

24 Damas y Damitas, núm. 149, 6 de mayo de 1942, p. 11.

\section{(이)(1)}


Las páginas de Damas y Damitas fueron el escenario donde se libró la batalla entre las empresas productoras de aceite. De tal forma, mientras Cocinero y Olavina apelaron a las historietas, donde los varones chef enseñaban a cocinar a las amas de casa, el aceite La Patrona de Swift ensayó una estrategia original. El anuncio se llamó "La Patrona pregunta" y su fin era invitar a las lectoras de Damas y Damitas y a todas las usuarias de aceite La Patrona a realizar un test con el propósito de conocer cuánto sabían acerca del producto. El comercial mostró un listado de diez preguntas y el rostro de la mujer que lo había superado con calificación "sobresaliente". ${ }^{25}$ Justamente, dicha dama era Carmela Horne de Burmeister, por entonces presidenta de la Asociación Argentina del Sufragio Femenino. La moraleja era: hasta la más visible de las defensoras del voto femenino sabía cocinar a la perfección con aceite La Patrona. Páginas arriba sostuvimos que la publicidad, además de vender, intervino con fuerza performativa sobre la condición femenina. Incorporar al anuncio la figura de Horne de Burmeister implicó orientar, más allá de lo comercial, en torno a una postura sociopolítica. La dama citada representó a las sufragistas que, dejando al margen reclamos como el divorcio o la libertad de empleo que en cierto sentido contradecían los mandatos del catolicismo recuperados incluso por la misma revista Damas y Damitas, bregaron exclusivamente por los derechos políticos de las mujeres. A su vez, el comercial aparecía emplazado en una revista que, en repetidas notas, se posicionó en defensa del voto femenino. No obstante, el reclamo se inscribió en el marco de las posturas conservadoras y simpatizantes con los valores católicos. Por lo tanto, se exigió que aquella mujer, esposa, madre y dueña del hogar también pudiese, con su voto, elegir gobernantes, pero siempre con miras a perpetuar y mejorar su gobierno del hogar (Barrancos, 2006, t. 4; 2008). En este punto, las sufragistas eran mujeres cocineras domésticas.

Finalmente, la empresa Gallo también aportó sus productos: aceite y arroz. Para ello recurrió a dos estrategias: la promoción del recetario Gallo y las recetas de cocina. La primera fue utilizada también, entre otras, por firmas como Maizena o Swift; la segunda, en cambio, fijó el cometido de promocionar las ventajas de utilizar sus productos más la fórmula culinaria que permitía explotar tales virtudes.

${ }^{25}$ Damas y Damitas, núm. 256, 24 de mayo de 1944, pp. 39, 42.

\section{(ㅇ)(1) $\$$}


ACEITE GALLO REGALA COMIDAS DELICIOSAS

¡Este Aceite de Calidad Superior, asegurará el éxito de sus comidas! Su sabor sutilmente DIFERENTE, tiene el poder mágico de convertir el plato más sencillo en un manjar exquisito. ¡Pruébelo señora!

\section{LANGOSTINOS AL WHISKI}

$1 \mathrm{~kg}$ de langostinos, $1 / 2$ taza de aceite GALLO, $1 / 2$ cebolla finamente picada, 1 vasito de whisky, sal, papitas a la cucharita, mejillones sin caparazón, 20 gr de manteca, 1 cucharada colmada de harina, 200 gr de leche, 200 gr de crema de leche, sal y pisca de cayena.

Saltear ligeramente los langostinos pelados, en el aceite, en el que se habrá dorado la cebolla, se le agrega el whisky, se le prende luego, se deja arder unos cuantos segundos, apagar, condimentar con buen gusto y retirarlos de la cacerola dejándolos al calorcito.

A la salsa de la cacerola se le agrega la manteca, la harina, la leche, la crema de leche, se cocina a fuego lento y se revuelve hasta que hierva, condimentar con sal y la cayena. Servir los langostinos cubiertos con su salsa y alrededor colocar las papitas a la cucharita salteadas con manteca y los mejillones sin caparazón. ${ }^{26}$

Ingredientes, procedimientos y productos genéricos, entre los que sólo se destacó el aceite de la marca, fueron las líneas del estilo con que se transcribió la receta. Un plato sofisticado que, al incorporarle aceite Gallo, alcanzaría su máximo sabor. Como hemos visto, las páginas de Damas y Damitas habilitaron un espacio de expresión para las empresas nacionales productoras de aceite. La necesidad de imponer el sello nacional, erradicando así la costumbre de consumir el producto de importación, provocó la germinación de diferentes marcas en el rubro que debían adquirir visibilidad, conquistando el gusto de las consumidoras. Para ello se interpeló directamente a la mujer como ama de casa, madre y cocinera. Este proceso se aceleró al superar los problemas económicos planteados por la crisis de 1930. Así, a partir de 1935 las industrias locales reorientaron sus producciones, y el aceite, como bien de consumo, adquirió relevancia en el marco de una sociedad de consumo donde la mujer aparecía como eje y móvil.

${ }^{26}$ Damas y Damitas, núm. 71, 6 de noviembre de 1940, p. 25.

\section{(ㅇ)(1) $\$$}




\section{A MODO DE CIERRE}

Acabamos de reseñar el modo en que la revista de Emilio Ramírez resolvió la transmisión del saber culinario entre mujeres, fueran autoras o lectoras/ aprendices. Este semanario imprimió sus particularidades: la cocina colonizó el campo de la economía doméstica; la figura de la mujer experta y profesional en el rubro se distinguió con nombre, apellido e imagen: Julia Bourdieu. Bajo el rango de profesora, Julia fue una mujer que, irrumpiendo en el espacio público, adquirió renombre pero también un estatus económico: mujer asalariada. Esta actividad, ¿ponía en riesgo la felicidad de su hogar? ¿O enseñar a cocinar era una tarea políticamente correcta para las integrantes del género femenino? Entendemos que la segunda premisa es la que justificó el trabajo extrahogareño de las profesoras de economía doméstica, también llamadas ecónomas. Llevando consigo las sartenes y cacerolas, las mujeres extendieron sus quehaceres y saberes más allá del hogar. Algunos elementos de la ciencia las ayudaron en la tarea y, entonces, se convirtieron en especialistas públicas de los saberes domésticos.

El producto del trabajo de las expertas estuvo dirigido a una mujer práctica, cocinera, ama de casa y madre pero también con capacidad y derecho al voto. A su vez, la mujer fue consumidora de utensilios de cocina así como de ingredientes y, para ello, la oferta la interpeló y elevó al lugar de destinataria única. Una mujer lectora que, en el caso de esta revista, provenía de los sectores sociales medios bajos preferentemente emplazados en centros poblacionales alejados de las grandes ciudades. Justamente, la interpelación por medio de la correspondencia y las preguntas de las lectoras dan cuenta de ello. El ferrocarril y el correo postal fueron la clave que articuló el diálogo entre la editorial y las mujeres.

Finalmente: ¿qué era cocinar, para Damas y Damitas?

Dijo alguien una vez, y lo confirma la experiencia, que es el arte de cocinar uno de los factores primordiales para retener la felicidad. La mujer debe saber cocinar; debe saber cocinar bien. Y no sólo para hacer alarde de ello, sino para merecer el elogio del esposo y hacer así, que en ninguna parte pueda hallarse él tan gratamente como en su hogar.

Es por eso que todas las publicaciones de carácter femenino dedican sendos espacios a las recetas de cocina, cosa que hacemos también nosotros. Solamente que DAMAS Y DAMITAS ha dado un paso más en esta materia y ha instalado en pleno centro de la Capital, en la Avenida de Mayo 1229, $6^{\circ}$ piso,

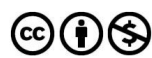


un salón de actos especialmente dedicado a darles clase de cocina práctica a sus amigas. ${ }^{27}$

La mujer debe saber cocinar bien para garantizar la felicidad de su hogar pero también para retener al esposo. Dos cuestiones que se solidarizaban entre sí en dirección al logro de la armonía familiar. Ese saber, lejos de estar inscrito en la naturaleza femenina, debía adquirirse al experimentar la vida y, para ello, todas las publicaciones femeninas presentaron secciones culinarias. Claro que la generalización sirve al editor para plantear luego su diferencia. Todas publicaron recetas de cocina, pero Damas y Damitas hizo algo más: creó el Instituto Superior de Educación Femenina. En él las principales transmisoras fueron mujeres: el nombre de Julia Bourdieu se reprodujo en todas las ediciones y anuncios de la revista. Aunque muchas veces estuvo acompañada por cocineros varones, ella fue quien hegemonizó la tarea. Por otra parte, la editorial supo armonizar el discurso de la ecónoma con la publicidad y para ello explotó el paratexto de la página. Julia no recomendaba marcas pero la revista, sutilmente, sí lo hizo al incorporar múltiples anuncios alrededor de las lecciones culinarias. Como producto comercial, Damas y Damitas disparó actos de consumo en una doble dirección: en relación con el mercado editorial pero también con el de los productos femeninos y domésticos, entre los cuales los del rubro alimentario fueron destacados.

Promediando el siglo $\mathrm{xx}$, tímidamente las mujeres adquirieron visibilidad pública, intelectual y política. Sin embargo, experiencias como las que ilustran el accionar femenino en las páginas de nuestro semanario aluden a la frágil inclusión femenina en el espacio público. Justamente, lo que la sección culinaria de la revista pone en relieve es que la pericia femenina, lejos de abrazar la totalidad del saber culinario, operó en un ámbito específico y restringido a las cosas del hogar, de la vida privada. Esta propuesta culinaria estaba orientada a difundir entre las mujeres principios alimentarios ligados tanto a la salud y al cuidado como al halago y al agasajo de la familia en el núcleo íntimo, ya sea como esposas o como parte del servicio doméstico. La editorial asumió este mandato y lo delegó en la figura de Julia. Se confió en que, mientras esta última enseñaba a cocinar, las damas y damitas lectoras replicarían las recetas y, en esa gimnasia, reforzarían su lugar de mujeres en la sociedad.

${ }^{27}$ Damas y Damitas, núm. 169, 23 de septiembre de 1942, pp. 55.

\section{(ㅇ)(1) $\$$}




\section{LISTA DE REFERENCIAS}

Armstrong, N. (1987). Deseo y ficción doméstica. Madrid: Cátedra.

Austin, J. (1998). Cómo hacer cosas con las palabras. Barcelona: Paidós.

Barrancos, D. (2006). La conquista del sufragio femenino en el Río de la Plata. En I. Morant (dir.), Historia de las mujeres en España y América Latina. Del siglo xx a los umbrales del XXI (t. 4, pp. 511-533). Madrid: Cátedra.

Barrancos, D. (2008). Mujeres, entre la casa y la plaza. Buenos Aires: Sudamericana.

Bassi, Á. (1920). Gobierno, administración é higiene del hogar. Curso de ciencia doméstica. Buenos Aires: Cabaut y Cía. Editores.

Batticuore, G. (2005). La mujer romántica. Lectoras, autoras y escritores en la Argentina 1830-1870. Buenos Aires: Edhasa.

Bontempo, P. (2012). Editorial Atlántida: un continente de publicaciones 1918-1936. Buenos Aires: Universidad de San Andrés.

Bouvet, N. (2006). La escritura epistolar. Buenos Aires: Eudeba.

Butler, J. (2001). El género en disputa. El feminismo y la subversión de la identidad. Buenos Aires: Paidós.

Caldo, P. (2009). Mujeres cocineras. Hacia una historia sociocultural de la cocina, Argentina a fines del siglo XIX y primera mitad del xx. Rosario: Prohistoria.

Caldo, P. (2012). Una disciplina con urbanidad: la economía doméstica. Aproximaciones a la problemática desde el Monitor de la Educación Común. En C. Kaufmann (dir.), Ahorran, acunan y martillan. Marcas de urbanidad en los escenarios educativos argentinos (primera mitad del siglo xx) (pp. 171-201). Paraná: Editorial de la Universidad Nacional de Entre Ríos.

Caldo, P. (2013a). Las cocineras de La Capital. Lectoras, amas de casa, ecónomas, consumidoras y saberes femeninos: una experiencia rosarina: 1930-1945. Sociedad y Economía, 24, 47-70. Colombia.

Caldo, P. (2013b). Libros, cocina e inmigración. Una propuesta culinaria con aires rosarinos. Rosario: El Ombú Bonsái.

Chartier, R. (1994). Los secretarios. Modelos y prácticas epistolares. En R. Chartier, Libros, lecturas y lectores en la Edad Moderna (pp. 284-314). Madrid: Alianza Universidad.

Chartier, R. (1999). Cultura escrita, literatura e historia. Conversaciones con Roger Chartier. México: FCE.

Cott, N. (1993). Mujer moderna, estilo norteamericano: los años veinte. En G. Duby y M. Perrot (dirs.), Historia de las mujeres. El siglo xx. Guerras, entreguerra y postguerra (t. 9, pp. 91-107). Madrid: Taurus.

Fischler, C. (1995). El (h)omnívoro. El gusto, la cocina y el cuerpo. Barcelona: Anagrama.

\section{(ㅇ)(1) $(9$}


Gay, P. (1992). La experiencia burguesa. De Victoria a Freud. La educación de los sentidos (t. 1). México: FCE.

Gayol, S. y Madero M. (ed.) (2007). Formas de historia cultural. Buenos Aires: Prometeo ediciones.

Giard, L. (2006). Hacer de comer. En M. de Certeau, L. Giard y P. Mayol, La invención de lo cotidiano. Habitar, cocinar (t. 2, pp. 151-255). México: Universidad Iberoamericana de Estudios Superiores de Occidente.

Gutiérrez, L. y Romero, L. A. (1995). Sectores populares, cultura y política. Buenos Aires en la entreguerra. Buenos Aires: Editorial Sudamericana.

Liernur, J. (1997). El nido en la tempestad. La formación de la casa moderna en la Argentina a través de los manuales y artículos sobre economía doméstica (18701910). Entrepasados, 13, 7-36. Buenos Aires.

Llomovatte, S. (1989). Analfabetismo y analfabetos en Argentina. Buenos Aires: Miño y Dávila Editores.

Nari, M. (1995). La educación de la mujer (O acerca de cómo cocinar y cambiar pañales a su bebé de manera científica). Mora, 1, 31-45. Buenos Aires.

Nari, M. (2004). Políticas de maternidad y maternalismo político, Buenos Aires, 1890-1940. Buenos Aires: Biblos.

Morant, I. (2006). Mujeres e historia. En I. Morant (dir.), Historia de las mujeres en España y América Latina. De la Prehistoria a la Edad Media (t. 1, pp. 7-16). Madrid: Cátedra.

Ortiz Gaitán, J. (2006). Casa, vestido y sustento. Cultura material en los anuncios de la prensa ilustrada (1894-1939). En A. de los Reyes (coord.), Historia de la vida cotidiana en México. Siglo xx. La imagen iespejo de la vida? (t. 5, vol. II, pp. 117-155). México: FCE.

Pérez, I. (2012). El hogar tecnificado. Familias, género y vida cotidiana 1940-1970. Buenos Aires: Biblos.

Pite, R. (2013). Creating a Common Table in Twentieth-Century Argentina: Doña Petrona, Women \& Food. Estados Unidos: TUNCP.

Revel, J.-F. (1996). Un festín en palabras. Historia literaria de la sensibilidad gastronómica desde la antigüedad hasta nuestros días. Barcelona: Tusquets.

Rocchi, F. (1999). Inventando la soberanía del consumidor: publicidad, privacidad y revolución del mercado en Argentina, 1860-1940. En F. Devoto y M. Madero (dir.), Historia de la vida privada en Argentina. La Argentina plural: 1870-1930 (t. 2, pp. 301321). Buenos Aires: Taurus.

Saítta, S. (1998). Regueros de tinta. El diario Crítica en la década de 1920. Buenos Aires: Sudamericana.

Sennett, R. (2009). El artesano. Barcelona: Anagrama.

\section{(이요 $(3$}


Ulanovsky, C. (2005). Paren las rotativas. Diarios, revistas y periodistas (1920-1969). Buenos Aires: Emecé.

Zemon Davis, N. (2006). Pasión por la historia. Entrevista con Denis Crouzet. Valencia: PUV.

\section{OTRAS FUENTES}

Archivos

ABNm Archivo de la Biblioteca Nacional de Maestros. Ciudad de Buenos Aires.

ABA Archivo de la Biblioteca Argentina "Juan Álvarez". Ciudad de Rosario.

АвСм Archivo de la Biblioteca del Consejo de Mujeres de la Ciudad de Rosario.

ABPed Archivo de la Biblioteca Provincial "Eudoro Díaz". Ciudad de Rosario.

\section{Hemerografía}

Damas y Damitas, 1939-1944, Buenos Aires.

El Monitor de la Educación Común, 1910-1915, Buenos Aires.

El Hogar, 1935-1939, Buenos Aires. 